take nearly 12 months to drill. It might then be possible to make an informed decision on whether to attempt commercial exploitation of the country's geothermal resources in the latter part of the $1980 \mathrm{~s}$.

If a positive decision were taken at that stage a third phase of development could begin with drilling of production holes, the planning of distribution systems and the stimulation of the potential market. The use of geothermal energy on any significant scale could not be expected before the turn of the century. This timetable is probably about the fastest which is practicable, and if desirable it could easily be lengthened; it would, however, mean that geothermal power became available about the time that production from the North Sea oil and gas fields began to drop significantly, and Britain changed from being a net exporter of oil to an importer once more.

Any consideration of the geothermal prospects of the UK, however, goes beyond the question of the heat which may be extracted from warm rocks of the upper crust. Experiments have been going on for some years at the Los Alamos Scientific Laboratory in the United States with a view to generating fractures artificially to permit water circulation both through rocks which are naturally impermeable, and through those which are so deeply buried in the crust that natural pores and fissures have normally closed. If these experiments were successful, it could become feasible to use such "hot rocks" to heat circulating water sufficiently for the generation of electricity.

The economic viability of such a scheme would be much enhanced by improvements in deep drilling methods; at present drilling costs roughly double for every $2 \mathrm{~km}$ increase in hole depth. Such a development would increase the available geothermal resource by more than a factor of 10 and free it from the geographical constraints which limit the use of warm water. The national long term geothermal strategy should, therefore, be seriously re-appraised if the Los Alamos experiments are promising. But no one should pretend that geothermal energy will solve the UK's energy problem; a small and possibly highly profitable resource, on the other hand, probably does exist-it is also a resource for the exploitation of which there are no large savings of scale, so that piecemeal development to satisfy local requirements is possible.

\section{No complacency}

It is probably fair to say that in the present world economic climate a country cannot afford not to investigate its geothermal resources further. It might be asked whether it is proposed to carry out the UK's geothermal exploration sufficiently rapidly; at present there is neither the drilling capacity nor sufficient trained man- power to mount an extensive crash programme, but even if there were it would not necessarily be more effective than a phased and progressively increasing effort over the next 10 years. The essential point is that no one be lured into a false sense of energy complacency during the next two decades of oil abundance, to the detriment of the development of other resources on which everyone will later depend.

A few may wish to ponder the point that many of the UK's large power stations reject hot water at temperatures which are regarded as suitable for geothermal exploitation in other parts of the world, and perhaps to question the wisdom of today continuing to charge a government authority with the limited mandate of generating electricity at the lowest possible price. And for those to whose lot it falls from time to time to defend the role of "pure science" in straitened economic circumstances, it is worth pointing out that the study of terrestrial heat flow which was until two years ago one of the most esoteric, albeit fascinating, branches of geophysics, has overnight become directly "relevant" and applied. Had not the Natural Environment Research Council (NERC) supported two university groups in this fields for a number of years, the UK would have completely lacked the technical expertise with which to implement fully its present geothermal programme.

\title{
Adjust, amend and heal
}

\section{The face of big science is changing constantly. Wil Lepkowski reports from Berkeley, California, on the way a famous laboratory has tried to adapt}

$\mathrm{O}$ SCAR WILDE was once heard to say of an old acquaintance, "There goes a man with a promising past." One might be tempted to direct the same comments at the Lawrence Berkeley Laboratory of Berkeley, California, where eight men have won Nobel Prizes for work in high energy physics, nuclear physics, nuclear chemistry, and photosynthesis. All winners, save the famed, forceful Ernest Orlando Lawrence, still live and form a solid command of senior directors who continue to chart the fortunes of the facility.

It is clear that the time of grand high drama in research is over at the old Lawrence Radiation Laboratory. For one thing, its support now comes from the Energy Research and De-

Research for this article was supported by the Center for Science in the Public Interest. velopment Administration (ERDA), whose mission is much more broad and ambitious than that of its predecessor, the Atomic Energy Commission (AEC). For another, the research budget for the things the Rad Lab always did best no longer arises at the rate it once did. And for a third, ERDA's new mission is not only much broader that the AEC's but is focusing its formula on industrial commercialisation of energy research and development, chiefly big scale systems.

Physics remains the most potent resource of the Lawrence Berkeley Laboratory (LBL). But the Laboratory is no longer the mecca for the brightest young minds seeking achievement through that once unique $\mathrm{Rad}$ Lab combination of men and machines. The men might still be around (and the use of the word "men" is deliberate, for the Laboratory is distinctly male dominated), but the machines are not. High energy physics is no longer done on site. The famed Bevatron is used now for cancer research and treatment and for nuclear physics. Officials say a new and exciting era could come into being through the Positron-Electron Project with Stanford University. In that project Stanford's Linear Accelerator would inject electrons and positrons into a new storage ring and the two particles would collide to produce energy patterns of unprecedentedly fine detail. But critics note that the new machine will not be at Berkeley but at Stanford. Laboratory officials may say it doesn't matter, but it really does. The place to be will be Stanford.

\section{Sinking sensation}

One thus hears oddments of commentary in the labs, and on the bus that shuttles researchers between the University of California campus and the Laboratory, that LBL is "sinking". The precise reasons are hard to track down because the Laboratory is no longer laying people off and the research budget is rising-from the current $\$ 47$ million to around $\$ 60$ million by the end of the next fiscal year. The sinking sensation is easily 
explained on psychological groundsanxiety over a vanishing pride and autonomy. Fundamental physics is no longer choice at LBL. Money in that field-once LBL's pride-is hard to come by. "The motto at this place once was, "why use lead when gold will do,", comments one researcher. LBL has had to become austere since 1970 and still is searching for a guiding star.

In 1970 the Atomic Energy Commission was still in existence. But its basic research budget was beginning to drop and LBL, along with AEC's seven other national laboratories, was forced to cut projects and personnel. The Laboratory formed an environmental division which with some success sought funds from agencies other than AEC. Still, the mood continued downward. As the concern over energy rose, the environment division became the energy and environment ( $E$ and $E$ ) department. By 1974, ERDA was created and with it an injection of energy research dollars. $\mathrm{E}$ and $\mathrm{E}$ will attain a budget of nearly $\$ 17$ million by next year.

$\mathrm{E}$ and E's acting director Robert Budnitz, a physicist, literally bubbles with optimism over the future of at least his division. Programmes include geothermal power, solar energy, fusion, and energy conservation, and the enthusiasm a visitor unerringly sees comes from scientists who like their work and know that someone who funds it appreciates it.

But LBL must still live with the fact that it is no longer the centre for intellect and excitement in basic science. ERDA, in fact, defines it as a general purpose laboratory uniquely linked to a great university. The hope is that $\mathrm{LBL}$ will utilise university scholars in law, economics and the social sciences to integrate energy research and technology with their application. One always wonders about the effectiveness of this kind of activity under an agency whose theme is big systems. The work may be funded but will it make a difference? And even more fundamentally, will it be any good anyway? Yet, such work is supremely important in an era of rising terrorism and nuclear proliferation.

\section{A style that suits?}

An issue that is not being tackled directly as yet is whether the management style of LBL is really suitable for the kind of work that needs doing for the development of energy research. LBL created what Alvin Weinberg has called Big Science-the need to expend large sums of money on big machines to carry out research on the smallest particles of matter. The Lawrence Laboratory owes most of its Nobel Prizes to that style of research emphasising machines, teams, and

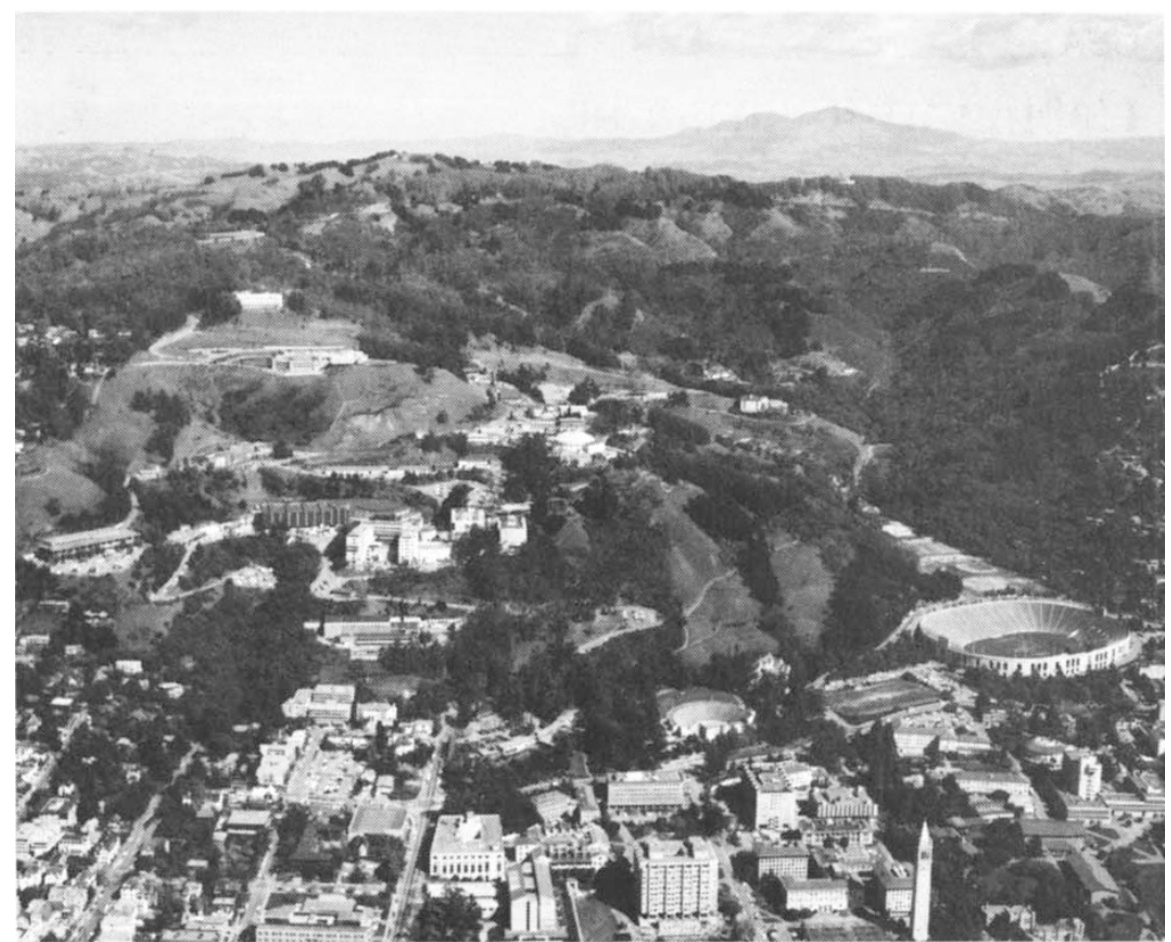

The Lawrence Berkeley Laboratory, California

discipline. But was the work really scientifically creative? Or was it creative engineering in the service of science?

One critic, physicist Robert Yaes of Memorial University, St. John's Newfoundland, thinks LBL's science has been over-rated. He said the Berkeley group was more interested in building larger and larger machines rather than with "doing experiments with the ones they had." One of the most significant discoveries in nuclear physics, nuclear fission, he says, was made by Hahn, Strassman, Meitner, and Frisch in Europe, "even though the Lawrence group had the world's most intense neutron beam." Similarly, the first nuclear disintegrations were made by Cockroft and Walton with an electrostatic generator that produced protons of only several hundred $\mathrm{KeV}$.

"In short", he says after citing other examples, "even though the Berkeley group possessed beams of energy and intensity available nowhere else in the world, the most significant discoveries were still being made by the "string and sealing wax' people in Europe".

There is growing debate over whether large scale technology is in society's best interests, with its tendency toward more and more control by a technical elite, towards the necessity of producing elaborate security structures around it, and toward increasing social fragility out of the possibility of breakdown. It may be that at least one highly sophisticated laboratory would serve ERDA well by emphasising the "string and sealing wax" approach to energy research and development through a focus on small systems. At the very least ERDA might put aside one laboratory to question prevailing philosophy and probe the basics of energy systems. At the moment it has no such place-a place that preserves and nourishes first principles.

\section{ERDA taking a view}

ERDA is studying the future role of the national laboratories in light of its mission to commercialise energy technology. It is asking practical questions about how one goes about linking their research and development functions with industrial development and demonstration. In the case of LBL, it is serious about integrating research at the University of California, which is contract manager of the Laboratory, with research at LBL.

But ERDA is also undecided about its overall research management strategy. It talks of regional programmes and projects and speaks of using the national laboratories somehow in the regionalisation of energy research. At the same time it says many laboratories, especially Berkeley, have a broad spectrum of capability in many fields. And all the while, ERDA policies are subject to political whims, since their Associate directors are all politically appointed. It is little wonder LBL officials are confused and worried. It is a centre with a rich tradition in research, and once bursting with pride and confidence. Now it searches for a prevailing philosophy against a backdrop of an agency that cannot yet say exactly how it plans to steer its own ship. 